\title{
BMJ Open Evaluation of an early career clinical academic training programme using the CIPP model
}

\author{
Elaine Burke (D), Martina Hennessy
}

To cite: Burke E, Hennessy M. Evaluation of an early career clinical academic training programme using the CIPP model. BMJ Open 2021;11:e052965. doi:10.1136/ bmjopen-2021-052965

- Prepublication history and additional supplemental material for this paper are available online. To view these files, please visit the journal online (http://dx.doi.org/10.1136/ bmjopen-2021-052965)

Received 06 May 2021 Accepted 14 October 2021
Check for updates

(C) Author(s) (or their employer(s)) 2021. Re-use permitted under CC BY-NC. No commercial re-use. See rights and permissions. Published by BMJ.

School of Medicine, Trinity College Dublin, Dublin, Ireland

Correspondence to

Dr Elaine Burke;

burkee13@tcd.ie

\section{ABSTRACT}

Objectives This study describes the successful implementation and outputs of a combined clinical academic training programme for doctors in their first postgraduate year in Ireland, the Academic Internship Track (AIT).

Design The AIT was evaluated using the Context, Input, Process and Product model. Literature reviews, meetings with key stakeholders, reviews of similar established programmes overseas, a survey of undergraduate medical students, exit survey, scientific outputs and career trajectory monitoring were all implemented in the programme evaluation.

Setting The AIT represents collaboration amongst all six intern training networks in Ireland.

Results Key stakeholders indicated support and significant interest in establishing the AIT. The input evaluation informed programme design which incorporates protected time to carry out a research project, a named supervisor, a bursary and access to dedicated study days. Since the programme's launch in 2017 , there has been $100 \%$ uptake of posts and $0 \%$ attrition. Exiting participants indicate high levels of satisfaction with the programme; $92 \%$ reported having benefited from participation. Over $90 \%$ intend remaining in Ireland in both the immediate and longer terms. Fifty-seven per cent of participants in the first 3 years of the programme had succeeded in publishing a research article or review paper in a peerreviewed journal.

Conclusions Now in its fourth year, AIT remains a highly sought-after programme and is perceived to be beneficial to one's career. Participants in the programme have contributed significantly to their field of interest despite being in the earliest career stages. The programme has the potential to help retain medical talent in Ireland.

\section{BACKGROUND}

Clinical academics (or clinician scientists) occupy a crucial role in healthcare systems, bridging a gap between research and patient care. Through their combined clinical and academic practice, they have the potential to identify research questions relevant to patient care and to translate research from bench to bedside. ${ }^{1-4}$ A strong research culture is associated with improved patient outcomes. ${ }^{5}$ Despite the importance of the role, there are concerns that it is under threat: in the USA,

\section{Strengths and limitations of this study}

This is the first study to describe the successful implementation of a combined clinical-academic training programme for junior doctors in Ireland in their first postgraduate year.

- The Context, Input, Process and Product evaluation model was a useful and appropriate method to evaluate the training programme.

- Equitable stakeholder input was key to the programme's successful evaluation and implementation.

- The search for research outputs was conducted by one researcher using one database (PubMed).

- It was not possible to compare the scientific outputs of participants in the programme with a control group.

the clinical academic workforce is ageing, with the average age at which a first independent NIH grant is awarded approaching 43. A leaky pipeline compounds the problem: onethird of young investigators with mentored NIH grants never apply for independent R01 grants, and many more are lost at later career stages. ${ }^{6}$ Similar problems exist in Australia and New Zealand, where the ability to recruit and retain clinical academics is potentially outstripped by an increase in demand for undergraduate medical education. ${ }^{7}$ Action is required to continue to attract talented graduates to careers in clinical academic practice. ${ }^{8}$

International literature suggests that those who engage with research early in their clinical careers will continue to do so. Graduates of the UK's Academic Foundation Programme (UKAFP) are over forty times more likely to progress to specialty academic training compared with graduates of the standard foundation programme $(9.5 \%$ vs $0.2 \%){ }^{9}$ A US review of 25 years of National Institutes of Health (NIH)-sponsored Medical Student Research Fellowship programmes found that up to half of former participants $(n=1000)$ considered themselves to be working in academic medicine, and the vast majority had conducted additional research after their 
medical student experience. ${ }^{10}$ Publication during residency is recognised as a determinant of the capacity to publish in a future career. ${ }^{112}$ In psychiatry, for example, the decision to pursue a research career is already well established by residency and very few who have less than the highest level of interest in research by that time eventually enrol in research career tracks. Together these indicate the crucial importance of early influences ${ }^{13}$.

\section{Ireland's context}

Opportunities for clinical research in Ireland are increasing. There has been considerable investment in clinical research infrastructure over the last decade. There now exists seven Clinical Research Facilities nationwide, multiple Clinical Trial Networks and Science Foundation Ireland-funded research institutes across the university and healthcare sector. Ireland has retained its reputation and position in the top 10 most innovative countries in Europe. ${ }^{14}$ The Irish government has pledged to build a strong research and innovation base in Ireland with the aim of becoming a Global Innovation Leader. ${ }^{15}$ This has prompted expansion of the number of Health Research Board funded clinician scientist awards, as a result academic capacity has increased in cancer, immunology, personalised medicine, neuroscience, ageing, bioinformatics and medical devices.

If opportunities for clinical research are increasing, clinical training and education must provide a workforce that is able to avail of these opportunities. Prior to 2017 , there was no combined clinical and academic training programme in Ireland for junior doctors at any level. In July 2017, the academic internship track (AIT) was launched, it provides a 1-year combined clinical and academic training programme to junior doctors in their first postgraduate year (interns). Currently in its fourth year, we offer an evaluation of the programme's development and success.

\section{Programme evaluation}

Context, Input, Process and Product model of evaluation

The Context, Input, Process and Product (CIPP) model includes formative and summative assessments with an emphasis on not only proving that a programme works, but also seeking areas for improvement. Key to the process is equity, and engagement is sought with all stakeholders in a fair and balanced manner ${ }^{16} 17$ (table 1).

\section{Context evaluation}

A context evaluation is similar but more comprehensive than a needs assessment as it also incorporates an assessment of problems, assets and opportunities. ${ }^{16} \mathrm{~A}$ literature review identified a need to provide training pathways for clinical academics to build and sustain the workforce. During the early stages of programme development, meetings were held with three groups who were key stakeholders: the Intern Network Executive, the body responsible for delivering intern training and assessment; the Irish Medical Council's Education Committee who oversee intern education and training, and the Health Service Executive's National Doctors Training and Planning, the body responsible for ensuring the Irish Health Service is provided with the appropriate number of medical specialists. All stakeholders were in support of the development of an academic track for internship whose aims are to:

- Provide opportunities for doctors at the beginning of their careers to continue or develop research, education and healthcare leadership and management skills.

\section{Table 1 Academic internship track evaluation model (adapted from Stufflebeam and Coryn ${ }^{16}$ )}

\section{CIPP model of evaluation}

\begin{tabular}{lll}
\hline Type of evaluation & Questions asked & Methods \\
\hline Context & What educational need is being met? & Literature review \\
& What goals should be pursued to meet the & Meetings with key stakeholders \\
& needs? & Online survey of undergraduate medical students \\
Input & What are the most promising approaches to & Literature review \\
& meeting the educational need? & Curriculum review of similar programmes \\
& What might some of the barriers to & Meeting with Director of UKAFP, an established \\
& successful implementation of the & programme \\
& programme be? & Online survey of undergraduate medical students
\end{tabular}

$\begin{array}{ll}\text { Process } & \text { To what extent was the programme carried } \\ \text { out as planned? }\end{array}$

Review of recruitment to process: post uptake and attrition Survey of exiting academic interns seeking feedback on programme

Product To what extent did the programme effectively address the original objectives?

Review of scientific outputs of previous participants in the programme

Feedback from exiting interns on career intentions Monitoring of career trajectory and retention in Ireland

CIPP, Context, Input, Process and Product; UKAFP, UK's Academic Foundation Programme. 
- Promote scientific discovery and sustained academic development within the context of contemporary clinical practice.

- Retain medical talent in Ireland.

Funding was subsequently provided for 24 posts nationally, representing $\sim 3 \%$ of all intern posts.

Medical students may also be considered key stakeholders, so an anonymous online survey was distributed to medical students in their fourth (penultimate) year of training; respondents indicated a high level of interest in a potential academic internship. ${ }^{18}$

\section{Input evaluation}

A literature review was undertaken to investigate approaches to combined clinical academic training programmes for junior doctors at the earliest career stages. The most similar programme to the Academic Intern Track in Ireland is the UK Academic Foundation Programme (UKAFP). The programme design and curriculum were examined, and a meeting was held with the programme director who provided further information and advice on programme design and implementation.

The literature review also revealed barriers to junior doctors' participation in clinical research which include time constraints owing to clinical/workplace duties, lack of statistical knowledge and research training, and lack of supervisors. ${ }^{19-21}$

The survey of fourth-year medical students asked what elements of a clinical academic training programme would be of greatest importance: they agreed that protected time within the working week, a named supervisor and access to training on basic and advanced research skills would be important or very important. ${ }^{18}$

Collating the advice, evidence from the literature and feedback from students, the AIT programme was designed to incorporate: protected time within the working week, usually occurring during one 3-month rotation during which time is divided equally between clinical and academic work; a named academic supervisor; funding in the form of $\mathrm{a} € 2000$ bursary to cover research and travel costs for the year; and study days and seminars to provide training in research, education and leadership skills.

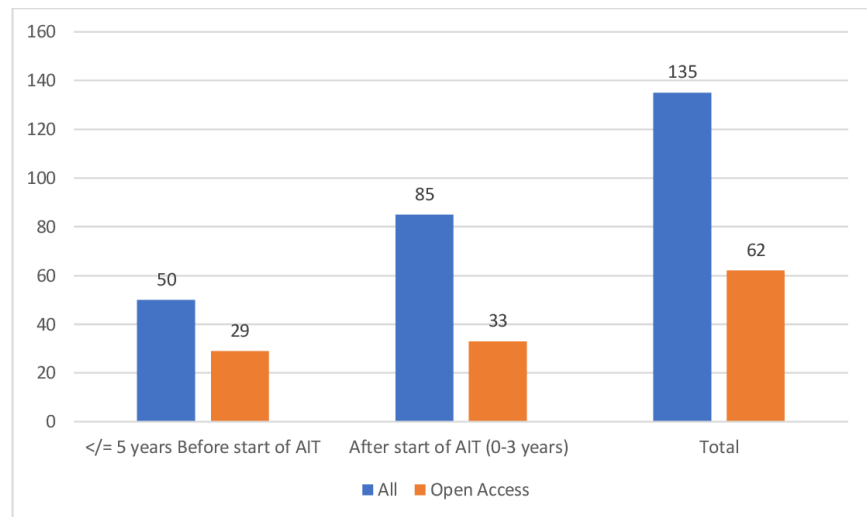

Figure 1 Peer-reviewed publications of first three cohorts of academic interns $(n=72)$. AIT, Academic Internship Track.

\section{Process evaluation}

Uptake of AIT posts

Now in its fourth year, the AIT has seen 72 academic interns complete the programme with a current cohort of 24 due to complete training in July 2021. Similar numbers of candidates apply to the academic track annually, with initial applications outnumbering posts by about 16 to 1 . There has been $100 \%$ uptake of posts each year, and $0 \%$ attrition from the programme.

\section{Feedback from exiting academic interns}

An anonymous online survey was distributed to the exiting interns of the 2017/2018 and 2018/2019 cohort $(n=48)$ (online supplemental file 1). Twelve interns out of 24 responded in 2018 and 21/24 in 2019 giving an overall response rate of $69 \%(n=33)$.

In the first year of the programme, $92 \%$ indicated that their experience of the clinical component of the year was good or excellent, and $83 \%$ indicated that the quality of experience of the academic part of the year was good or excellent. Of that first cohort, $42 \%$ had also applied for or considered applying for the UKAFP prior to accepting the post on the AIT. Fifty-eight per cent held another third level qualification.

Ninety-two per cent of respondents perceived a benefit from participating in the AIT. As well as learning new skills, producing papers for publication and learning good time-management skills, participants appreciated the opportunity to work closely with mentors and get a sense of life as a clinical academic. Several participants mentioned that they found the overall experience to be very fulfilling. Eighty-three per cent would recommend the academic track to a friend. The 2018/2019 survey showed very similar results.

\section{Product evaluation}

Early scientific outputs

An individual search on PubMed for each of the 72 AIT participants was conducted between 10 June 2020 and 20 June 2020. Only original, peer-reviewed research papers, essays or review articles published $\leq 5$ years prior to graduation and any time postgraduation were included, with letters, commentary, abstracts, conference proceedings and editorials excluded.

One hundred and thirty-five articles which named participants in the AIT from 2017 to $2019(\mathrm{n}=72)$ as authors were identified. Of these, 50 were published in the five years prior to graduation and 85 either during or at 1-2 years postcompletion of the AIT (figure 1).

Forty-one of the 72 former academic interns $(56.94 \%)$ have achieved publication of a research paper/review article in a peer-reviewed journal to date; a substantial number of publications were open access. Removing one very prolific individual from the cohort still indicates a high level of publication, with 94 total publications, 33 prior to the academic track and 61 during or after, with a range of $0-8$ publications. In this group, there was an average of 0.46 publications per intern prior to the 
Table 2 Top five publications by journal impact factor (published after start of AIT)

\begin{tabular}{lll}
\hline Journal & No of publications & Impact factor* $^{*}$ \\
\hline British Journal of Anaesthesia & 2 & 6.199 \\
Free Radical Biology \& Medicine & 1 & 6.17 \\
The American Journal of Sports Medicine & 6 & 6.057 \\
Journal of Clinical Investigation Insight & 1 & 6.014 \\
Annals of Medicine & 1 & 5.435 \\
\hline
\end{tabular}

*Impact factors recorded at time of database review, June 2020

AIT, Academic Internship Track.

academic track and 0.86 publications during or after the academic track, however, it must be noted that the duration of time since commencement of the academic track and hence the amount of data available varied for each cohort.

The quality of publications based on journal impact factor is also an indicator for success of the programme (table 2).

Academic interns develop their own project proposal and identify an area of research that is of interest to them. On reviewing the project titles and primary supervisors' occupation, we found a total of 28 specialties represented, with oncology, anaesthetics, obstetrics and gynaecology, orthopaedic surgery and paediatrics being the most represented specialties (figure 2). Analysis suggests interns publish predominantly in the specialty represented by their academic track projects: 64 of the 85 publications attributed to academic interns during and after the AIT are within the same field as their academic track project.
Feedback from exiting interns indicated outputs other than publication or presentation, these included outreach activities, gaining additional qualifications, achieving awards and accolades for their academic work, gaining teaching experience and learning new research skills.

\section{Career trajectory and retention in Ireland}

In 2017/2018 on formal reporting, 10/12 participants confirmed they were remaining in Ireland for their first Senior House Officer (SHO) year, with two planning to travel abroad. However, informally 22/24 (or 92\%) planned to stay in Ireland and subsequently did. In $2018 / 2019$, none of the respondents reported an intention to apply for a training scheme abroad and just $10 \%$ planned to take up non-training scheme work abroad. Of the remainder, most $(42.6 \%)$ planned to take up a training post in Ireland; others planned to join a GP scheme, take a stand-alone post or undertake further study.

The first AIT cohort provided open-ended responses regarding 5-year career intentions, most reported that

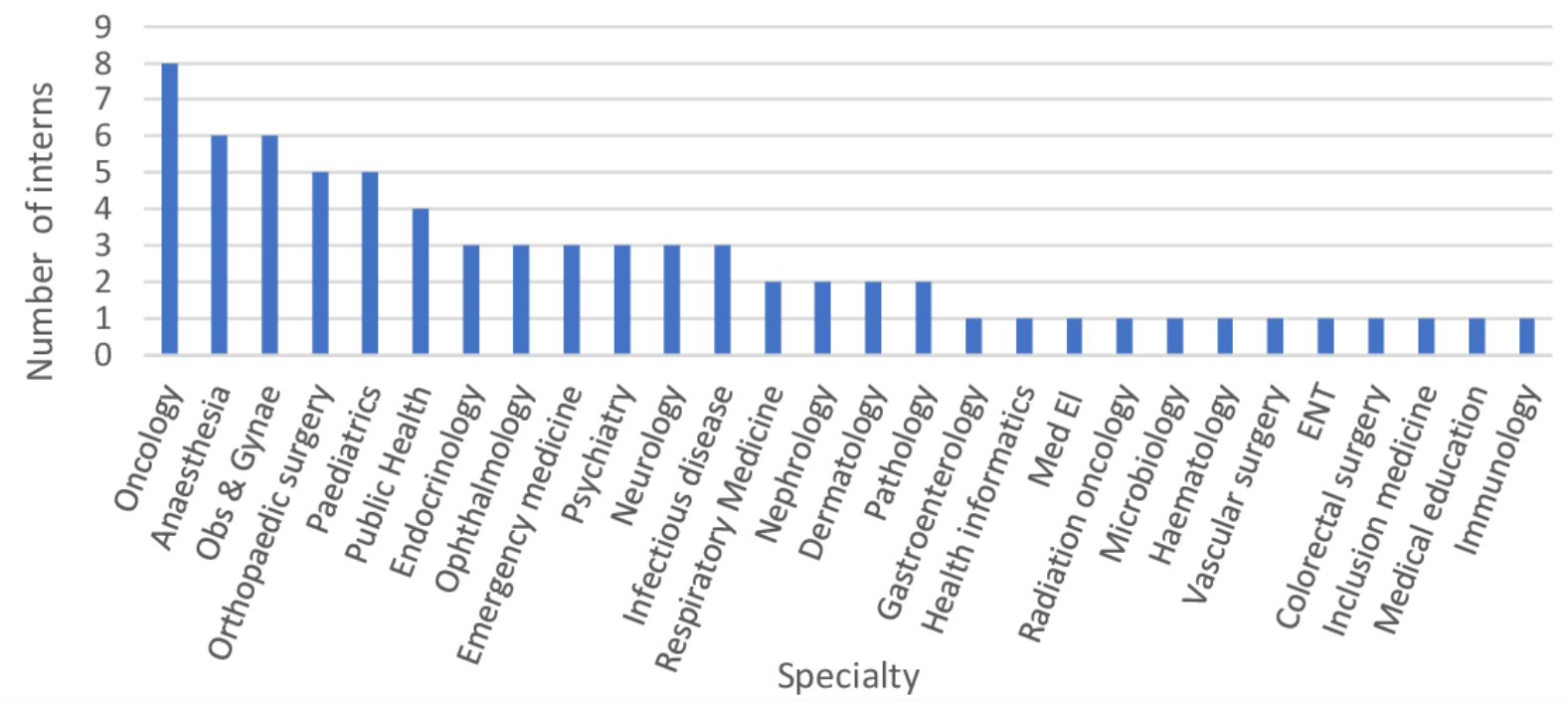

Figure 2 Specialties represented by academic track interns ( $n=72)$. ENT, Ear, Nose and Throat surgery. Med El, Medicine for the Elderly. 


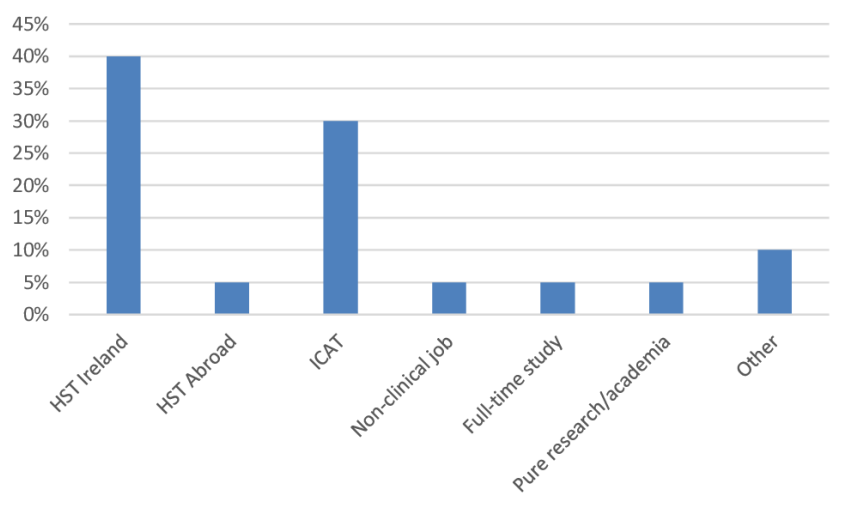

Figure 3 Longer-term career plans.

they were aiming for higher specialist training (HST) schemes without indicating a specific location; only one indicated a preference to train abroad. By the second cohort, $66.7 \%$ indicated an aspiration for HST in Ireland and the Irish Clinical Academic Training (ICAT) programme, a combined specialist training and $\mathrm{PhD}$ programme. Other preferences such as non-integrated research/academia are shown (figure 3).

With the programme just in its fourth year, it is too early to determine its effects on career trajectory, however, this will be monitored as a key outcome going forward.

\section{DISCUSSION}

Evaluation of the first 4 years of the AIT in Ireland has shown three key findings: a demand to develop key research skills by early career junior doctors, the capacity to translate these skills and contribute to a chosen field of study, and that satisfying these needs may contribute to the retention of this valuable expertise.

The survey of undergraduate students indicated a significant interest in the programme, and this has been borne out in the recruitment process. Similar numbers apply for academic internship annually, with applications received far exceeding the places available. In 4 years, we have never had a post unfilled, and no-one has left the programme early. The level of interest in the programme has been sustained, even during the uncertainties of the COVID-19 pandemic, indicating the perceived quality of the programme and its benefit to one's career. It is likely that there is great scope for expansion of the programme.

Even at the earliest career stage, participants in a combined clinical academic training programme have the potential to contribute substantially to their field of interest. The majority of participants in the first 3 years of the academic track have already contributed to publications as named authors and it is anticipated that this number will rise significantly given the lengthy process of manuscript preparation and publication. Publications either during or after the academic track outnumber publications in the 5 years before the academic track (when participants would have been undergraduate medical students). A substantial number of publications
$(38.8 \%)$ were open access, and many were published in high calibre journals.

Data from a similar programme run in the UK, the UKAFP, indicates that on exiting the 2-year programme, $33 \%$ of participants have submitted or prepared papers for publication. ${ }^{22}$ While it is not a direct comparison, $57 \%$ of AIT participants having achieved publication at 0,1 and 2 years postacademic track would suggest that they are prolific compared with their peers.

Medical doctors at all levels, clinical academics or not, are thought to publish at a rate of 0.47 papers per year. Publication rate is much lower at the earliest career stages. ${ }^{23}$ Taking 1 year of the academic track, 2018/2019 as an example, the 24 participants succeeded in publishing at an average rate of 1.27 papers each per year in the 2 years since their academic internship start date, indicating a rate of publication over twice that of the average doctor, despite being at the earliest career stage.

There are some limitations of the database review: it was conducted by one researcher only, and only one database (PubMed) was searched. Therefore, it is possible that papers which should have been attributed to participants in the programme were missed, whereas others may have been misattributed. Further, it was not possible to compare the research outputs of participants with a control group, for example, a group of interns who did not participate in the academic track, due to a lack of other identifying factors such as field of interest or supervisor.

It is possible that creating such opportunities at an early career stage can help retain doctors in Ireland in both the immediate and longer term. Participants in the AIT tend to remain in Ireland after completion of the programme; in contrast, almost two thirds of interns who have completed the standard intern-training programme plan to emigrate abroad at least for a year. ${ }^{24}$ Ireland has ongoing problems recruiting and retaining health personnel and despite producing the most doctors among Organisation for Economic Co-operation and Development countries, it remains below average for practising doctors per 1000 population. A national doctor retention strategy has been in place since 2015 but has enjoyed limited success. ${ }^{25}$ Factors influencing the higher retention rate may include intrinsic factors such as a focused career plan. Alternatively, academic interns having fostered relationships with other researchers may wish to continue to build their networks, emphasising the importance of mentors to early career clinical academics.

A different perspective might suggest that the academic track creates greater job satisfaction and hence greater retention. Burn-out is high among Irish junior doctors, and that this contributes to the decision to emigrate. ${ }^{26}$ A highly demanding job combined with low or scarce resources can negatively impact on employee wellbeing, whereas a highly demanding job with high levels of support and resources can have a positive impact. ${ }^{27}$ Exiting academic interns express high levels of satisfaction with the programme. It's possible provision of 
additional resources to achieve their academic goals (in the form of time, funding and mentorship) enhance the academic interns' experiences of intern year, mitigate against burn-out and encourage their retention within the Irish healthcare system, however, further research would be required to investigate this hypothesis. It is likely multiple factors are at play.

The AIT is not without its challenges: a small number of posts nationally means many excellent candidates miss out on posts each year, limited funding for study days and other events can impact on their delivery, and the arrival of COVID-19 has necessitated a move to online educational sessions as well as a potential increase in conflict between clinical responsibilities and academic goals. Despite these challenges, it remains a training programme that is highly regarded among students and interns and is perceived to be of value to one's career. While it is early days yet in terms of career trajectory, it is hoped that this positive early experience will provide these talented graduates with a stepping-stone towards further clinical academic training, launching their careers as clinical academics and helping to build and sustain this workforce for the future.

Acknowledgements The authors would like to thank the following for their contribution to the creation and evaluation of the academic internship: the Dublin South East Intern Network team: Professor Finbarr O'Connell, Mr Evan Blake, Ms Aine Wade, Dr Peter Wheen, Dr Owen Thorpe; the Intern Network Executive, the Irish Medical Schools Council, the Irish Medical Council, the HSE NDTP and Professor Derek Gallen. The authors also wish to acknowledge Professor Aileen Patterson for her contributions to the paper.

Contributors The first author (EB) made substantial contributions to the conception and design of the study, data acquisition, interpretation and analysis. She developed the exit survey and searched the literature for papers attributable to former participants in the AIT. She drafted and revised the manuscript and approved it for final submission. The second author (MH) made substantial contributions to the conception and design of the study, data interpretation and analysis. She reviewed the initial drafts of the manuscript and approved the final draft for submission. Both authors have full access to all the data in the study and can take responsibility for the integrity of the data and the accuracy of the data analysis. EB is acting as guarantor.

Funding The authors have not declared a specific grant for this research from any funding agency in the public, commercial or not-for-profit sectors.

Competing interests EB is employed by Trinity College and oversees the implementation of the Academic Internship Track in the Dublin South-East Intern Network. MH is employed by Trinity College Dublin and is the Director for Internship for the Dublin South East Intern Network.

Patient consent for publication Not applicable.

Provenance and peer review Not commissioned; externally peer reviewed.

Data availability statement All data relevant to the study are included in the article or uploaded as online supplemental information.

Supplemental material This content has been supplied by the author(s). It has not been vetted by BMJ Publishing Group Limited (BMJ) and may not have been peer-reviewed. Any opinions or recommendations discussed are solely those of the author(s) and are not endorsed by BMJ. BMJ disclaims all liability and responsibility arising from any reliance placed on the content. Where the content includes any translated material, BMJ does not warrant the accuracy and reliability of the translations (including but not limited to local regulations, clinical guidelines, terminology, drug names and drug dosages), and is not responsible for any error and/or omissions arising from translation and adaptation or otherwise.

Open access This is an open access article distributed in accordance with the Creative Commons Attribution Non Commercial (CC BY-NC 4.0) license, which permits others to distribute, remix, adapt, build upon this work non-commercially, and license their derivative works on different terms, provided the original work is properly cited, appropriate credit is given, any changes made indicated, and the use is non-commercial. See: http://creativecommons.org/licenses/by-nc/4.0/.

ORCID iD

Elaine Burke http://orcid.org/0000-0002-9885-8763

\section{REFERENCES}

1 Hall AK, Mills SL, Lund PK. Clinician-Investigator training and the need to pilot new approaches to recruiting and retaining this workforce. Acad Med 2017;92:1382-9.

2 Glasper A. Escaping the ivory tower: emancipation of the modern clinical academic. Br J Nurs 2012;21:496-7.

3 Windsor J, Garrod T, Talley NJ, et al. The clinical academic workforce in Australia and New Zealand: report on the second binational Summit to implement a sustainable training pathway. Intern Med $J$ 2017;47:394-9.

4 Foster S. The need for clinical academic roles. Br J Nurs 2018;27:229.

5 Ozdemir BA, Karthikesalingam A, Sinha S, et al. Research activity and the association with mortality. PLoS One 2015;10:e0118253-e.

6 Schafer Al. The vanishing physician-scientist? Transl Res 2010;155:1-2.

7 Willcox S. Creating and sustaining the next generation of the clinical academic workforce. A discussion paper prepared for Medical Deans Australia and New Zealand. Health Policy Solutions Pty Ltd 2011.

8 Rees M. The role of the clinical academic, 2014. Available: https:// www.researchgate.net/publication/275350789_The_Role_of_the_ Clinical_Academic

9 Office UFP. 2019 F2 career destination report, 2019. Available: https://foundationprogramme.nhs.uk/resources/reports/

10 Solomon SS, Tom SC, Pichert J, et al. Impact of medical student research in the development of physician-scientists. J Investig Med 2003;51:149-56.

11 Yang G, Zaid UB, Erickson BA, et al. Urology resident publication output and its relationship to future academic achievement. $J$ Urol 2011;185:642-6.

12 Macknin JB, Brown A, Marcus RE. Does research participation make a difference in residency training? Clin Orthop Relat Res 2014;472:370-6.

13 Silberman EK, Belitsky R, Bernstein CA, et al. Recruiting researchers in psychiatry: the influence of residency vs. early motivation. Acad Psychiatry 2012;36:85-90.

14 Hollanders H. European innovation Scoreboard 2020; report No.: ISSN 2467-4435. Brussels: European Commission, 2020.

15 Department of Jobs, Enterprise and Innovation. Innovation 2020 Ireland's strategy for research and development, science and technology. Innovation and Investment Division; 2015. https:// enterprise.gov.ie/en/Publications/Publication-files/Innovation-2020. pdf

16 Stufflebeam DL, Coryn CL. Evaluation theory, models and applications. 2nd Edition. Hoboken: John Wiley \& Sons, 2014

17 Frye AW, Hemmer PA. Program evaluation models and related theories: AMEE guide No. 67. Med Teach 2012;34:e288-99.

18 Burke $\mathrm{E}$, Teeling $\mathrm{M}$, Hennessy $\mathrm{M}$. Introduction of an academic internship in Ireland: views of undergraduate medical students. Ir J Med Sci 2019;188:1025-32.

19 Clancy AA, Posner G. Attitudes toward research during residency: a survey of Canadian residents in obstetrics and gynecology. J Surg Educ 2015;72:836-43.

20 Mitwalli HA, Al Ghamdi KM, Moussa NA, Perceptions MNA. Perceptions, attitudes, and practices towards research among resident physicians in training in Saudi Arabia. East Mediterr Health $J$ 2014;20:99-104.

21 Clough S, Fenton J, Harris-Joseph $\mathrm{H}$, et al. What impact has the NIHR academic clinical fellowship (ACF) scheme had on clinical academic careers in England over the last 10 years? A retrospective study. BMJ Open 2017;7:e015722.

22 Kelley T. National evaluation of the academic Foundation programme. UK Foundation Programme; 2016.

23 Rørstad K, Aksnes DW. Publication rate expressed by age, gender and academic position - a large-scale analysis of Norwegian academic staff. J Informetr 2015;9:317-33.

24 Cronin F, Clarke N, Hendrick L, et al. The impacts of training pathways and experiences during intern year on doctor emigration from Ireland. Hum Resour Health 2019;17:74.

25 Brugha R, Clarke N, Hendrick L, et al. Doctor retention: a crosssectional study of how Ireland has been losing the battle. Int $J$ Health Policy Manag 2020;x (x:1-11. 
26 Hannan E, Breslin N, Doherty E, et al. Burnout and stress amongst interns in Irish hospitals: contributing factors and potential solutions. Ir J Med Sci 2018;187:301-7.
27 Page KM, Milner AJ, Allisey A, et al. Wellbeing-enhancing workplaces. In: Jarden A, Oades L, Slade M, eds. Wellbeing, recovery and mental health. Cambridge: Cambridge University Press, 2017: 289-99. 